\title{
Study on Indigestible Foreign Body in Rumen and Reticulum of Cattle Slaughtered at Bahir Dar Municipal Abattoir, Ethiopia
}

\author{
Selamawit Fentahun Ali ${ }^{*}$, Zegeye Awoke \\ School of Veterinary Medicine, Wollo University, Dessie, Ethiopia
}

\section{Email address:}

yanuselam@yahoo.com (S. F. Ali)

${ }^{*}$ Corresponding author

\section{To cite this article:}

Selamawit Fentahun Ali, Zegeye Awoke. Study on Indigestible Foreign Body in Rumen and Reticulum of Cattle Slaughtered at Bahir Dar Municipal Abattoir, Ethiopia. International Journal of Animal Science and Technology. Vol. 3, No. 3, 2019, pp. 41-47. doi: 10.11648/j.jjast.20190303.12

Received: July 22, 2019; Accepted: August 14, 2019; Published: September 4, 2019

\begin{abstract}
A cross-sectional study was conducted from October 2016 to April, 2017 at Bahirdar municipal abattoir, Amhara National Regional State, to determine the prevalence of rumen and reticulum foreign bodies and to identify types of foreign bodies and associated risk factors for the occurrences of foreign bodies. The study animals were selected by using simple random sampling method from the total slaughtered animals. From the total of 384 examined cattle, $78(20.3 \%)$ were found positive for the occurrence of indigestible foreign bodies in rumen and reticulum. Prevalence of foreign body occurrence recorded in young $(<5$ years) 10 (11.23), adult (5-10 years) $34(15.38 \%)$ and in old $(>10$ years) $34(45.95 \%)$ respectively while the prevalence rate recorded in poor, medium and good cattle were $33(35.48 \%), 29(22.3 \%)$ and $16(9.93 \%)$. The types of foreign bodies encountered in rumen and reticulum were plastic, nails, wires, hair ball, clothes and key. Out of 78 positive cases of foreign body, $51(13.5 \%)$ were occurred in rumen, $21(5.5 \%)$ in reticulum and $6(1.5 \%)$ were encountered in both rumen and reticulum. Among the considered risk factors, age, stomach compartment and body condition score of the examined animals found highly significantly associated $(\mathrm{p}<0.05)$ with the occurrence of foreign bodies. The prevalence of rumen and reticulum foreign bodies was lower in local breed cattle $57(19.38 \%)$ than that of the cross breeds 21 (23.3\%). It was not stastically significant $(\mathrm{p}=0.999)$ between local and cross breed. In general, detection of the foreign bodies in rumen and reticulum causes loss of production and high mortality rate as well it has also impact on animal welfare. Hence, appropriate solid waste disposal system need to be implemented in the study area to prevent health risk of ruminants and environment.
\end{abstract}

Keywords: Abattoir, Bahirdar, Cattle, Foreign Body, Reticulum, Rumen

\section{Introduction}

Cattle play significant contribution in Ethiopian economy as a source of meat, milk, drought power, income, and foreign exchange. Sheep and goats are major source of income (cash) for the rural poor farmers in most parts of tropics including Ethiopia. Furthermore, they play an important role in providing export commodities, such as live animals, hides and skins to earn foreign exchanges [1]. However, the full exploitation of these resources is hindered by a combination of factors such as drought, poor genetic potential and backward animal husbandry practices and diseases [2]. Ingestion of foreign bodies by ruminants is extremely common especially in developing countries, like Ethiopia, where the standard of animal management is unsatisfactory and low nutritional statuses of ruminants have forced them to scavenge for food [3]. In Ethiopia, ruminants are very likely to be exposed to ingestion of indigestible foreign bodies of various sources, as they are mainly reared in urban, sub-urban and kept under an extensive type of management [4]. The bovine species does not have highly sensitive prehensile organs, such as lips and tongue, nor are a discriminating sense of taste and ingestion and lodgment of foreign bodies common due to indiscriminate feeding habits [5]. It is generally accepted that sheep and goats are highly selective feeders and ingest significantly less amount of 
foreign bodies compared to cattle [6].

The ingestion of foreign body is mainly related with nutritional deficiencies and feeding management and cause various problem in different organ of the animal, mainly in rumen and reticulum [7]. Entrance and migration of foreign bodies through the body tissues lead to many complications that differ according to the nature of the foreign body and the way of its entrance in to the tissues. TRP relatively common disease in cattle caused by the ingestion of foreign bodies in the reticulum swallowed metallic objects such as nail or pieces of wire fall directly on the reticulum or pass into the rumen and subsequently carried over the rumeno-reticular folds in to the cranioventral part of the reticulum [8].

Non metallic foreign bodies in the reticulo-rumen cause recurrent rumen tympani in adult dairy cattle, over a period of time, these materials, form large tight balls inside the rumen leading to anorexia decreased production and progressive loss of body condition [9]. The presences of foreign bodies in the rumen and reticulum also hamper the absorption of volatile fatty acids (VFA) and consequently reduction in the rate of animal fattening. The perforation of the wall of the reticulum allows leakage of ingesta and bacteria which contaminates the peritoneal cavity, resulting in local or diffuse peritonitis is the swallowed objects can also penetrate pleural cavity causing pleuritis and pneumonitis and into the pericardial sac causing pericarditis [10]. The condition is serious in our country usually in urban and peri- urban areas where extensive building are carried out and proper plastic material disposal is no conditioned and so thrown on roads and near the fence or anywhere and that is way our dairy cattle are dying mainly associated with foreign bodies [4].

In Ethiopia information regarding the magnitude and occurrence of fore stomach foreign bodies is very limited. The fact that rumen impaction by these foreign bodies is mainly asymptomatic in nature and only diagnosed in live animals if the material is accumulated in large amount and thus, it can be adequately studied in abattoirs [11]. The present study were therefore undertaken to assess the prevalence and identification of rumen and reticulum foreign bodies in cattle slaughtered at Bahirdar municipal Abattoir.

\section{Materials and Methods}

\subsection{Study Area}

The study was conducted from October 2016 to April 2017 on cattle's in Bahirdar municipal abattoir. Bahirdar is located at the geographic co-ordinates of $11^{\circ} 38^{\prime}$ North latitudes and $37^{\circ} 15^{\prime}$ East longitudes. The city is located at about $570 \mathrm{~km}$ away from Addis Ababa in North part of Ethiopia. The area is known for its water resources, lake Tana and Blue Nile river. The altitude of the area ranges from 1500-2300m above sea level. The area receives bimodal annual rain fall which has a range of $1200-1600 \mathrm{~mm}$ and the mean annual temperature is $23^{\circ} \mathrm{C}$ [12].

\subsection{Study Animals}

The study was conducted on 384 male apparently healthy slaughtered cattle at Bahirdar municipal Abattoir from October, 2016 to April, 2017. Animals were both local and cross breed cattle kept under extensive and semi intensive farming systems. Even though, the study animals were kept under broad range of management, animals in most of the rural areas were kept to graze pasture on grassland and supplementary feedings of crop residue when pasture in scarce especially during long dry season. In Bahirdar city, semi intensive management system was practiced and animals were feed with concentrate and hay. Nevertheless, attempts made in this regard revealed that majority of them were bought from nearby markets.

\subsection{Study Design}

A cross-sectional study was conducted from October, 2016 to April, 2017 to assess the prevalence of the rumen and reticulum foreign bodies and to identify the type of indigestible foreign bodies and their associated risk factors for the occurrence of foreign bodies. Breed, age, body conditions and stomach compartment affected were considered as risk factor for occurrence of foreign bodies. During the study time the animals were categorized into three as young, adult, and old and age of studied animals were estimated based on dentition pattern [13] and their body condition scoring was made based on their physical condition as poor medium and good were described by McCurin and Basser; Pruitt [13-14].

\subsection{Sampling Technique and Sample Size Determination}

Simple random sampling technique was employed to select the study animals and rumen and reticulum of individual animals were examined.

The sample size for this study would be calculated by considering $50 \%$ of the population about indigestible foreign body since there are no researches in the area before. Thus, the sample size would be determined according to [15] using $95 \%$ confidence interval and 0.05 absolute precision. This is calculated by using the following formula:

$$
\mathrm{N}=\frac{\left(1.96^{2}\right)(P \exp )(1-P \exp )}{d^{2}}
$$

Where,

$\mathrm{N}=$ required sample size.

$\mathrm{P}_{\text {exp }}=$ Expected proportion of population of indigestible foreign body are $50 \%$.

$\mathrm{d}=$ Desired absolute precision $(0.05)$

Therefore, the minimum sample size of the present study was 384 .

\subsection{Study Methodology}

\subsubsection{Ante Mortem Examination}

Each animal selected for the study was further indentified by providing a unique identification number that could be 
used for both antemortem and postmortem examinations of the animal and each animals mark for the identification by writing a code on its gluetal muscle by using marker. Antemortem examination on individual animals was done for assessment of age, breed, body condition. Age is categorized into young ( $<5$ years), adult (5-10 years) and old ( $>10$ years) based on dentition pattern, breed differentiation (cross and local) and also body condition (poor, medium and good) [13].

\subsubsection{Postmortem Examination}

In the postmortem examination rumen and reticulum were examined. Immediately after the animal was slaughtered in the evisceration stage, the stomach is carefully removed from the abdominal cavity and open and explored for the prevalence of any foreign by visualization and palpation. When the finding was positive, the site of fore stomach and type of the foreign bodies was recorded otherwise recorded as negative in postmortem record sheet.

\subsection{Data Management and Analysis}

The data obtained was coded in Microsoft excel and subjected to descriptive statistics and chi square in order to assess the magnitude of the difference of comparable variables using SPSS version 20. Software. Pearson chi square $\left(\mathrm{x}^{2}\right)$ test was employed to assess the existence of association between prevalence of the foreign bodies and different potential risk factors considered. For $\left(\mathrm{X}^{2}\right)$ test, $\mathrm{p}$ value $<0.05$ were considered significant where as $p$ value $>0.05$ considered non significant. Descriptive statistical analysis such as table was used to summarize and present the data collected. The total prevalence of rumen and reticulum foreign bodies was calculated as percentage by dividing total number of positive cattle for foreign bodies to the total number of cattle examined.

\section{Results}

\subsection{Over All Prevalence of Foreign Bodies}

From the total of 384 cattle examined for the presences of any foreign bodies $78(20.3 \%)$ animals had foreign bodies in their rumen and/or reticulum. From 78 positive cases of foreign body, $51(13.5 \%)$ were occurred in rumen while 21 $(5.5 \%)$ in reticulum and $6(1.5 \%)$ were found in both rumen and reticulum. Foreign bodies were plastic, cloth, wire, nail, hair ball and key. Plastic was more frequently encountered in the study animals.

\subsection{Prevalence of Foreign Bodies with Associated Risk Factors}

\subsubsection{Prevalence of Foreign Body in Relation to Animal Age}

From 89, 221 and 74 animals examined with the age of $<5$ year, 5-10 year and $>10$ year, $10(11.23 \%), 34(15.38 \%)$ and $34(45.95 \%)$ were found positive for foreign bodies ingestion respectively. There was significant difference $(p=0.00)$ between young, adult and old animals in the occurrence of foreign body in their fore-stomachs. Plastics were more frequently encountered foreign bodies in the fore-stomach of young cattle ( $<5$ years), plastic, cloth and hair was frequently encountered foreign bodies 5-10 year cattle and plastics, wire and clothes were more frequently recovered foreign bodies from the rumen and reticulum of old cattle ( $>10$ years) as indicated in Table 1.

Table 1. Prevalence and frequency of rumen and reticulum foreign bodies in association with age.

\begin{tabular}{|c|c|c|c|c|c|c|}
\hline \multirow{2}{*}{ Age } & \multicolumn{2}{|l|}{ result } & \multirow{2}{*}{ Total } & \multirow{2}{*}{ Prevalence } & \multirow{2}{*}{$\begin{array}{l}X^{2} \\
63.364\end{array}$} & \multirow{2}{*}{$\begin{array}{l}P \\
0.00\end{array}$} \\
\hline & Positive & Negative & & & & \\
\hline$<5$ years (young) & 10 & 79 & 89 & $11.23 \%$ & & \\
\hline $5-10$ years (adult) & 34 & 187 & 221 & $15.38 \%$ & & \\
\hline$>10$ years (old) & 34 & 40 & 74 & $45.95 \%$ & & \\
\hline Total & 78 & 306 & 384 & $20.3 \%$ & & \\
\hline
\end{tabular}

Table 2. Prevalenceand identified rumen and reticulum foreign bodies in association with age.

\begin{tabular}{|c|c|c|c|c|c|c|}
\hline \multirow{2}{*}{ Foreign bodies } & \multicolumn{6}{|l|}{ Age } \\
\hline & $<5$ years ( young) & 5-10 years (adult) & $>10$ years $($ old $)$ & Total & $\mathbf{X}^{2}$ & $\mathbf{P}$ \\
\hline Plastic & $6(1.6 \%)$ & $13(3.4 \%)$ & $12(3.1 \%)$ & 31 & \multirow[t]{12}{*}{63.364} & \multirow[t]{12}{*}{0.00} \\
\hline Cloth & $0(0 \%)$ & $9(2.3 \%)$ & $6(1.6 \%)$ & 15 & & \\
\hline Nail & $0(0 \%)$ & $2(0.5 \%)$ & $3(0.8 \%)$ & 5 & & \\
\hline Wire & $1(0.3 \%)$ & $2(0.5 \%)$ & $8(2.1 \%)$ & 11 & & \\
\hline Key & $1(0.3 \%)$ & $0(0 \%)$ & $3(0.8 \%)$ & 4 & & \\
\hline Plastic and cloth & $1(0.3 \%)$ & $1(0.3 \%)$ & $0(0 \%)$ & 2 & & \\
\hline Plastic and wire & $1(0.3 \%)$ & $1(0.3 \%)$ & $0(0 \%)$ & 2 & & \\
\hline Plastic and key & $0(0 \%)$ & $1(0.3 \%)$ & $0(0 \%)$ & 1 & & \\
\hline Plastic and nail & $0(0 \%)$ & $2(0.5 \%)$ & $0(0 \%)$ & 2 & & \\
\hline Hair & $0(0 \%)$ & $3(0.8 \%)$ & $2(0.5 \%)$ & 5 & & \\
\hline No foreign body & $79(20.6 \%)$ & $187(48.7 \%)$ & $40(10.4 \%)$ & 306 & & \\
\hline Total & 89 & 221 & 74 & 384 & & \\
\hline
\end{tabular}




\subsubsection{Prevalence of Foreign Body in Relation to Animal Breed}

Among the total 384 animals examined, 294 were local breeds and 90 were cross breed. In this study foreign bodies were detected in both breeds of cattle. The prevalence of rumen and reticulum foreign bodies were higher in cross breed cattle 21 $(23.3 \%)$ than that of the local breeds $57(19.38 \%)$. There was not stastically significant difference $(p=0.999)$ between local and cross breed as shown below in Table 3 .

Table 3. Prevalence and frequency of rumen and reticulum foreign bodies in association with breed.

\begin{tabular}{|c|c|c|c|c|c|c|}
\hline \multirow{2}{*}{ Breed } & \multicolumn{2}{|l|}{ Result } & \multirow{2}{*}{ Total } & \multirow{2}{*}{ Prevalence } & \multirow{2}{*}{$\begin{array}{l}X^{2} \\
5.490 \\
\end{array}$} & \multirow{2}{*}{$\begin{array}{l}P \\
0.999\end{array}$} \\
\hline & Positive & Negative & & & & \\
\hline Local & 57 & 237 & 294 & $19.38 \%$ & & \\
\hline Cross & 21 & 69 & 90 & $23.3 \%$ & & \\
\hline Total & 78 & 306 & 384 & $20.3 \%$ & & \\
\hline
\end{tabular}

Table 4. Prevalence and identified rumen and reticulum foreign bodies in association with breed.

\begin{tabular}{lllll}
\hline Foreign bodies & Local breed & Cross breed & Total & $\mathbf{X}^{2}$ \\
\hline Plastic & $23(6.0 \%)$ & $8(2.1 \%)$ & 31 & 5.490 \\
Cloth & $12(3.1 \%)$ & $3(0.8 \%)$ & 15 & 0.999 \\
Nail & $4(1.0 \%)$ & $1(0.3 \%)$ & 5 & 11 \\
Wire & $8(2.1 \%)$ & $3(0.8 \%)$ & 4 \\
Key & $3(0.8 \%)$ & $0(0.0 \%)$ & 2 & 2 \\
Plastic and cloth & $1(0.3 \%)$ & $1(0.3 \%)$ & 1 \\
Plastic and wire & $1(0.3 \%)$ & $1(0.3 \%)$ & 2 \\
Plastic and key & $1(0.3 \%)$ & $1(0.3 \%)$ & 5 & \\
Plastic and nail & $1(0.3 \%)$ & $1(0.3 \%)$ & 306 \\
Hair & $3(0.8 \%)$ & $2(0.5 \%)$ & 384 \\
No foreign body & $237(61.7 \%)$ & $69(17.7 \%)$ & 90 & \\
Total & 294 & 9 & \\
\hline
\end{tabular}

\subsubsection{Prevalence of Foreign Body in Relation to Body Condition}

From 93, 130 and 161 animals examined with poor, medium and good body conditions, 33 (35.48\%), 29 (22.3\%) and 16
(9.93\%) were positive for foreign body respectively. There was significant difference $(\mathrm{p}=0.00)$ between different body condition scores and foreign body distribution in rumen and reticulum Table 5.

Table 5. Prevalence and frequency of rumen and reticulum foreign bodies in association with body condition.

\begin{tabular}{|c|c|c|c|c|c|c|}
\hline \multirow{2}{*}{ Body condition } & \multicolumn{2}{|l|}{ Result } & \multirow{2}{*}{ Total } & \multirow{2}{*}{ Prevalence } & \multirow{2}{*}{$\begin{array}{l}X^{2} \\
50.352 \\
\end{array}$} & \multirow{2}{*}{$\begin{array}{l}P \\
0.00 \\
\end{array}$} \\
\hline & Positive & Negative & & & & \\
\hline poor & 33 & 60 & 93 & $35.48 \%$ & & \\
\hline Good & 16 & 145 & 161 & $9.93 \%$ & & \\
\hline Total & 78 & 306 & 384 & $20.3 \%$ & & \\
\hline
\end{tabular}

Table 6. Prevalence and identified rumen and reticulum foreign bodies in association with body condition.

\begin{tabular}{|c|c|c|c|c|c|c|}
\hline \multirow{2}{*}{ Foreign bodies } & \multicolumn{6}{|c|}{ Body condition } \\
\hline & poor & Medium & Good & Total & $X^{2}$ & $\mathbf{P}$ \\
\hline Plastic & $11(2.9 \%)$ & $12(3.1 \%)$ & $8(2.1 \%)$ & 31 & & \\
\hline Cloth & $8(2.1 \%)$ & $5(1.3 \%)$ & $2(0.5 \%)$ & 15 & & \\
\hline Nail & $3(0.8 \%)$ & $2(0.5 \%)$ & $0(0.0 \%)$ & 5 & & \\
\hline Wire & $8(2.1 \%)$ & $2(0.5 \%)$ & $1(0.3 \%)$ & 11 & & \\
\hline Key & $2(0.5 \%)$ & $2(0.5 \%)$ & $0(0.0 \%)$ & 4 & & \\
\hline Plastic and wire & $0(0.0 \%)$ & $2(0.5 \%)$ & $0(0.0 \%)$ & 2 & & \\
\hline Plastic and key & $0(0.0 \%)$ & $1(0.3 \%)$ & $0(0.0 \%)$ & 1 & & \\
\hline Plastic and nail & $1(0.3 \%)$ & $1(0.3 \%)$ & $0(0.0 \%)$ & 2 & & \\
\hline Hair & $0(0.0 \%)$ & $1(0.3 \%)$ & $4(1.0 \%)$ & 5 & & \\
\hline No foreign body & $60(15.6 \%)$ & $101(26.3 \%)$ & $145(37.8 \%)$ & 306 & & \\
\hline Total & 93 & 130 & 161 & 384 & & \\
\hline
\end{tabular}




\subsubsection{Prevalence of Foreign Body in Relation to the Stomach Compartment Affected}

From total 78 positive cases of foreign body, $51(13.5 \%)$ were occurred in rumen while $21(5.5 \%)$ in reticulum and 6 $(1.5 \%)$ in rumen and reticulum. Rumen harbored mostly plastic materials while reticulum was the major site for metallic objects. Occurrence of foreign body was strongly significant difference $(\mathrm{p}=0.00)$ in rumen and reticulum as shown in Table 7.

Table 7. Frequency of occurrence of foreign bodies in association with sites of fore stomach.

\begin{tabular}{llll}
\hline \multirow{2}{*}{ Site of forestomach } & Result & Prevalence & $\mathbf{X}^{\mathbf{2}}$ \\
\cline { 2 - 3 } & Positive & 1.08 & \\
\hline Rumen & 51 & $13.5 \%$ & \\
Reticulum & 21 & $5.5 \%$ & \\
Rumen and reticulum & 6 & $1.5 \%$ & \\
Total & 78 & $20.3 \%$ & \\
\hline
\end{tabular}

Table 8. Frequency and identified foreign bodies in association with site of fore stomach.

\begin{tabular}{|c|c|c|c|c|c|c|}
\hline \multirow{2}{*}{ Foreign bodies } & \multicolumn{6}{|c|}{ Site of fore stomach } \\
\hline & Rumen & Reticulum & Rumen and reticulum & Total & $\mathrm{x}^{2}$ & p-value \\
\hline Plastic & $30(7.8 \%)$ & $1(0.3 \%)$ & $0(0.0 \%)$ & 31 & 1.08 & 0.00 \\
\hline Cloth & $15(3.9 \%)$ & $0(0.0 \%)$ & $0(0.0 \%)$ & 15 & & \\
\hline Nail & $0(0.0 \%)$ & $5(1.3 \%)$ & $0(0.0 \%)$ & 5 & & \\
\hline Wire & $0(0.0 \%)$ & $11(2.9 \%)$ & $0(0.0 \%)$ & 11 & & \\
\hline Key & $0(0.0 \%)$ & $4(1.0 \%)$ & $0(0.0 \%)$ & 4 & & \\
\hline Plastic and cloth & $2(0.5 \%)$ & $0(0.0 \%)$ & $0(0.0 \%)$ & 2 & & \\
\hline Plastic and key & $0(0.0 \%)$ & $0(0.0 \%)$ & $2(0.5 \%)$ & 2 & & \\
\hline Plastic and nail & $0(0.0 \%)$ & $0(0.0 \%)$ & $2(0.5 \%)$ & 2 & & \\
\hline Hair & $5(1.3 \%)$ & $0(0.0 \%)$ & $0(0.0 \%)$ & 5 & & \\
\hline No foreign body & $0(0.0 \%)$ & $0(0.0 \%)$ & $0(0.0 \%)$ & 306 & & \\
\hline Total & 51 & 21 & 6 & 384 & & \\
\hline
\end{tabular}

\section{Discussion}

Ingestion of indigestible foreign materials by ruminants is a common worldwide problem reported by [16]. The present study revealed an overall prevalence of 78 (20.3\%) of rumen and reticulum foreign body in cattle slaughtered at Bahirdar Municipal abattoir. The present studies indicate prevalence of foreign bodies is approximately similar with the report of Rahel [17] who record $17.07 \%$ of prevalence of fore stomach foreign bodies in Hawasa Municipal Abattoir. The study wa slower than the report of Ismael et al. [18] who reported (77.41\%) adult dairy cattle cases having indigestible foreign bodies suffering from recurrent rumen tympani in Jordan and also Jagos. [19] Reported higher over all prevalence of foreign body in adult cows (51\%). These differences in the prevalence of foreign bodies between various areas might be due to differences in animal management systems and the extent of foreign body management both in the rural and/or urban areas and in the grazing areas. Ingestion of foreign bodies is associated with a shortage of forage [20] as well as increased pollution of grazing lands with indigestible materials [21]. If owners do not provide supplementary feed during feed shortages, their animals are likely to face a negative energy balance that will force them to ingest unusual materials including plastic, cloth, rope and even metallic objects [20].

In this study, highest prevalence 34 (45.95\%) of foreign bodies was detected in old cattle ( $>10$ year age) followed by adult cattle (5-10 years) $34(15.38 \%)$ and in young cattle ( $\leq 5$ year's age) $10(11.23 \%)$. This finding is agree with the work done by Abebe and Nuru [22] who recovered plastics, clothes and ropes at higher prevalence from the rumen and reticulum of old sheep and goats, Besides Hailat et al. Fromsa and Mohammed; Hailat etal.; Tesfaye and Chanie; Tiruneh and Yesuwork[6;23-26] and Desiye and Mersha [11] who found $(81.25 \%)$ of foreign bodies in cattle greater than 10 year age. Rahel [17] also reported (17.85\%) of the animals had higher frequency of foreign bodies in rumen and reticulum in the old age. This is because of more foreign bodies in older animals may be a result of the gradual accumulation of indigestible materials ingested over a prolonged period of time.

Higher prevalence of foreign body was observed in the cross breed cattle (23.3\%) than the local breeds (19.38\%). This finding are agree with the work of Desiye and Mersha [11] who found $70 \%$ in cross breed and $10.77 \%$ in local breed and Rahel [17] who reported fore stomach foreign bodies with the high prevalence of (58.82\%) in cross breeds. This might be due to associated with the level of body size, production and drought power which requires high demand of energy and nutrition, hence increase exposure for foreign bodies and the $p$ - value is not associated due to difference in origin of animals.

In this study, animals with poor body condition were found to be most affected with indigestible foreign bodies. This result was agree with the report of Hailatetal; Fromsa and Mohammed; Hailat et al.; Tesfaye and Chanie; Tiruneh and 
Yesuwork and Vanitha et al. [6, 23-27]. It is impossible in the current study to conclude whether the foreign bodies caused the loss of weight in animals or that animals in poor body condition were likely to have pica and hence pick up strange objects as a result. It is possible that animals are in poor body condition as a result of ingestion of indigestible foreign bodies that interfere with food digestion and absorption. The more frequent occurrence of rumen and reticulum impaction in emaciated and thin animals might be attributed to the interference of the foreign body with the absorption of volatile fatty acids, causing reduced weight gain. The results of this study are in agreement with Tesfaye and Chanie [25] in Jimma, South-west Ethiopia and Fromsa and Mohammed [23] in East Shoa, Ethiopia, Semiek a [28] in Egypt used radiography and found out that needles and nails were frequent. Fromsa and Mohammed [23] recovered plastic, leather, wire and hairballs in buffaloes and cattle. Hailat et al.[6] also recovered such indigestible foreign bodies as plastic bags, pins, nails, hairballs, ropes and leather. In this study plastic, hairballs, keys, nails, plastic bags and wire were recovered from the stomachs of cattle. This is not surprising, as these objects are in common usage in daily activities and are not disposed properly.

The highest frequency of occurrence of rumen and reticulum foreign bodies was detected at rumen (65.38\%). This finding was in general agreement with the findings of Abebe and Nuru; Tesfaye et al. and Roman and Hiwot [22, 29-30] this might be attributed to the larger rumen volume, the cumulative size/s and material composition of the foreign bodies and the types of materials, with metals and sharp objects tending to localize preferentially in reticulum [7] and many ingested feed goes to the rumen. This study also indicated that Metallic foreign bodies were most frequently recovered from reticulum, while non-metallic foreign bodies were detected from rumen. Metallic foreign bodies were most frequently recovered from reticulum due to retention of foreign bodies by the honey comb structure of the reticular mucosa and their heavy weight result in gravitational attraction force of these heavy foreign bodies to the ventral part of the forestomach.

Plastic was the most commonly encountered (39.7\%) foreign material in all study animals, followed by cloth $(19.2 \%)$. This finding is in general agreement with various reports from different areas of Ethiopia by Abebe and Nuru; Sheferaw et al. [22, 31] Nigeria by Igbokwe et al.; Remi Adewunmi et al. [32-33] and Jordan by Hailat et al. [20]. This indicates the widespread use of plastic bags in the areas and environmental pollution due to their improper disposal.

\section{Conclusion and Recommendations}

This study revealed an overall prevalence of $20.3 \%$ of foreign bodies in the fore stomach of cattle slaughtered at Bahirdar Municipal Abattoir. Ingested foreign bodies by cattle are divided into two main groups; the first category is foreign bodies of metallic origin and the second is foreign bodies of non-metallic origin. The types of foreign bodies that found in rumen and reticulum of cattle were plastics, clothes, key, hair ball, nails, and wires. More foreign bodies were found in the rumen (13.5\%) than the reticulum $(5.5 \%)$. Animals with poor body condition and old cattle are the most affected groups compared to that of good body condition and young cattle respectively. Hence, body condition score and age of animals are considered risk factors for the occurrence of foreign bodies. Therefore, degree of association is highly statistically significant $(p<0.05)$ for the occurrence of foreign body.

Based on the above conclusion the following recommendations are forwarded: Environmental pollution should be reduced by proper management of waste which reduces the chance of ingesting foreign bodies and cattle should be supplied with sufficient diet even if the season is dry in order to minimize the problem of ingestion of foreign bodies.

\section{Ethical Approval and Consent to Participate}

The study was prearranged and freedom from requiring ethical support from Wollo university, school of veterinary medicine. We have also got permission for access to data from the head of Bahirdar municipal abattoir.

\section{Competing Interests}

The authors declare that they have no competing interests.

\section{Authors' Contribution}

ZA and SF drafted the proposal and SF reviewed it. ZA took part in collecting foreign body from the forestomach and record the parameters of randomly selected animal during postmortem examination and Ante mortem examination respectively from Bahirdar municipal abattoir. SF provided valuable information on the subject of data analysis and the design of the study. SF and ZA participated in writing the manuscript. Both authors have read and approved the final manuscript.

\section{Acknowledgements}

We would like to acknowledge professionals who work in Bahirdar municipal abattoir and Wollo University, School of veterinary medicine for their all rounded contribution.

\section{References}

[1] CSA, (Central Stastical Agency), (2015) Federal Democratic Republic of Ethiopia. Central Statistical Agency (CSA). Agricultural sample Survey 2010 (2001 E. C). Report on livestock and live stock characteristics (Private peasant holding), Vol. 2, Addis Abeba.

[2] Ibrahim, H. (1998): Small ruminant production techniques. International Livestock Research Institute, Nairobi, Kenya. 
[3] Misk, A., Nigam, J. and Rifati, J. (1999): Management of foreign body syndrome in Iraqi cattle. Agricultural Practice. Pakistan Veterinary Journal, 5 (8): 91-121.

[4] Ramaswamy, V and Sharama, H. R. (2011): Plastic bags treat to environmental and cattle health: a retrospective study from Gondar city of Ethiopia. Environmental Management for Sustainable Development, 2: 7-12.

[5] Singh, A. P and Nigam, J. M. (1981): Radiography of the foreign bodies in the bovine. Bovine Practice 2: 7-13.

[6] Hailat, N., Nouh, S., Al-Darraj, A., Lafi, S and Al-Ani, F. (1997): Prevalence and pathology of foreign bodies (plastics) in Awassi sheep in Jordan. Small Ruminant Res., 24: 43-48.

[7] Radostits, O. M., Gay, C. C., Hinchcliff, K. W. and Constable, P. O (2007):Veterinary Medicine, a textbook of the diseases of Cattle, Horses, Sheep, Pigs and Goats. 10ed, Elsevier Limited, Pp. 337-352.

[8] Jones, T., Hunt, R. and King, N. (1997): Veterinary Pathology, 6 ed, USA, Pp. 1060-1061

[9] Jafarazadeh, S., Nowrouzian, Z. and Adibhashemi, F. (2004): The sensitivities and specificities of total plasma protein and plasma fibrinogen for the diagnosis of traumaticreticulo peritonitis in cattle. Preventive Veterinary Medicine, Pp 1-7.

[10] Cavedo, A., Latimer, K., Tarply, H. and Bain, P. (2004): Traumatic reticuloperitonitis (hard ware diseases in cattle veterinary clinical pathology clerkship program university of Georgia, Athens, Pp 1-4.

[11] Desiye, T. and Mersha, C. (2012): Study on Rumen and Reticulum Foreign Bodies in Cattle Slaughtered at Jimma Municipal Abattoir, South West Ethiopia. American-Eurasian Journal of Scientific Research, 7 (4): 160-167.

[12] ANRSAB (Amhara National Regional State Agriculture Bureau), (2011): Bahirdar animal health investigation and diagnostic center, Bahirdar, Ethiopia.

[13] Mc Curin, D. M. and Basser, J. M. (2006): Clinical text book for veterinary technicians. 6thed. Elsever Saunders. Pp: 224244.

[14] Pruitt, R. J. (1994): Personal Communication. South Dakota State University: Brookings. Pp. 14-30.

[15] Thrusfield, M. U. (2005): Veterinary Epidemiology. 3rd ed. Burgh, U. K: Black well science LTD, Pp: 182-189.

[16] Ghurashi, M., Seri, H., Bakheit, H. and Ashwag, M. (2009): Effect of surgical removal of foreign body from goat's rumen with special reference to the prevalence of foreign body in goats in Southern Darfur. Australian Journal Basic Application of science, 3 (2): 664-668.

[17] Rahel, M. (2011): Study on fore stomach foreign body in cattle Slaughtered Hawassa Municipal Abattoir, Ethiopia, DVM thesis Gondar University, Faculty of Veterinary Medicine, Gondar, Ethiopia, Pp. 3-9.

[18] Ismael, Z., Majabi, A and Al-Qudah, K. (2007): Clinical and surgical findings and outcome following rumenotomy in adult dairy cattle affected with recurrent rumen tympany associated with non-metallic foreign bodies. American Journal of Animal and Veterinary Sciences, 2: 66-70.
[19] Jagos, P. (1969): The ferroscopical investigation into the occurrence of foreign body in clinically health cattle. Veterinary Bull, 40: 856-873.

[20] Hailat, N., South, S., Darraji, A. and Majali, A. (1996): Prevalence and Pathology of foreign bodies (plastics) in Awassi sheep in Jordan. Small Ruminant Research, 24: 43-48.

[21] Tesfaye D., Daba D., Mekibib M. \& Fekadu A., (2012a). The problem of environmental pollution as reflected in the fore stomach of cattle: A postmortem study in Eastern Ethiopia', Global Journal of Environmental Research 6 (2), 61-65. 22.

[22] Abebe, F. andNuru, M. (2011): Prevalence of indigestible foreign body ingestion in small ruminants slaughtered at Luna export abattoir, East Shoa, Ethiopia, Journal of Animal and Veterinary Advances, 10 (12): $1598 \pm 1602$.

[23] Fromsa, A. and Mohammed, N., 2011, 'Prevalence of indigestible foreign body ingestion in small ruminants slaughtered at Luna Export Abattoir, East Shoa, Ethiopia', Journal of Animal and Veterinary Advances 10 (12), 15981602. http://dx.doi. org/10.3923/javaa.2011. 1598. 1602.

[24] Hailat, N., AI-Darraji, A., Lafi, S. and Barakat, S. (1998): Pathology of the rumen in goats caused by plastic foreign bodies in Jordan with reference to its prevalence and evidence of partial degradation. Small Ruminant Research, 30: 77-83.

[25] Tesfaye, D. and Chanie, M., 2012, 'Study on rumen and reticulum foreign bodies in cattle slaughtered at Jimma Municipal Abattoir, South West Ethiopia', AmericanEurasian Journal of Scientific Research 7 (4), 160-167.

[26] Tiruneh, R. and Yesuwork, H. (2010): Occurrence of rumen foreign bodies in sheep and goats slaughtered at the Addis Ababa Municipality Abattoir', Ethio. Vet. Jour, 14 (1): 91 100 .

[27] Vanitha, V., Nambi, A., Gowri, B. and Kavitha, S. (2010): Rumen impaction of cattle with indigestible foreign bodies. Journal of Veterinary and Animal Science, 6: 138-140.

[28] Semieka, M. (2010): Radiography of unusual foreign body in ruminants, Veterinary World, 3: 473-475.

[29] Tesfaye D., Yismaw S. \& Demissie T., 2012b, 'Ruminal and reticular foreign bodies in small ruminants slaughtered at Jimma Municipal Abattoir, Southwestern Ethiopia', Journal of Veterinary Advances 2 (8), 434-439.

[30] Roman, T. and Y. Hiwot, (2010): Occurrence of rumen fibrinogen for the diagnosis of traumatic foreign bodies in Sheep and Goat slaughtered at Addis Ababa Municipal Abattoir. Ethiopia Veterinary Journal, 14 (1): 91-100.

[31] Sheferaw D, Fikreysus G, Metenyelesh A, Tesfaye D and Ethana D. 2014. Ingestion of indigestible foreign materials by free grazing ruminants in Amhara region, Ethiopia', Tropical animal health andproduction. 46: 247-250.

[32] Igbokwe, I., Rolo, M. and Egwu, G. (2003): Rumen impaction in sheep with indigestible foreign bodies in the semi-arid of Nigeria. Small Ruminant Research, 49: 141-146.

[33] Remi-Adewunmi, B. D., Gyang, E. O. and Osinowo, A. O. (2004): Abattoir Survey of Foreign Body Rumen Impaction in Small Ruminants. Niger. Vet. Jour, 25, 32-38. 